\title{
Influência dos agregados leves de argila calcinada nas propriedades mecânicas de concretos estruturais
}

\section{Influence of calcined clay lightweight aggregates on the mechanical properties of structural concretes}

\footnotetext{
1,2 Faculdade de Zootecnia e Engenharia de Alimentos - USP. Av. Duque de Caxias Norte, 225 - Campus da USP - CEP: 13635-900 - Pirassununga/SP.

e-mail: desantis.bruno@gmail.com; j.a.rossignolo@gmail.com
}

\begin{abstract}
RESUMO
Este trabalho tem por objetivo a avaliação da influência dos agregados leves de argila calcinada nas propriedades mecânicas de concretos estruturais. Os agregados leves de argila calcinada foram produzidos pelo processo de extrusão, com valores de umidade próximos dos limites de plasticidade das massas cerâmicas. Após a confecção dos agregados leves de argila calcinada, foram confeccionados corpos de prova de concreto com agregados leves de argila calcinada, argila expandida e basalto. Os concretos foram submetidos aos ensaios de massa específica e abatimento do tronco de cone, no estado fresco e de resistência à compressão, resistência à tração por compressão diametral, módulo de deformação e massa específica no estado endurecido. Os resultados desta pesquisa indicaram que os agregados tem grande influência nas propriedades mecânicas dos concretos, sendo que os agregados leves de argila calcinada apresentaram características e desempenho intermediários quando comparados aos agregados leves de argila expandida e agregados convencionais (basalto).
\end{abstract}

Palavras-chave: Agregados leves de argila calcinada, concretos leves, concretos estruturais.

\section{ABSTRACT}

This paper aims to evaluate the influence of calcined clay lightweight aggregates on the mechanical properties of structural concretes. Lightweight aggregates were extruded with moisture content close to their plastic limits. After the manufacture of calcined clay lightweight aggregates, concrete specimens were made using calcined clay lightweight aggregates, expanded clay and basalt. Specimens were characterized by fresh specific mass, slump test (fresh condition), compressive strength, tensile strenth, modulus of elasticity and specific mass (cured state). Results of this research indicates that aggregates have great influence on the mechanical properties of concretes and calcined clay lightweight aggregates showed intermediated characteristics when compared with expanded clay and basalt aggregates.

Keywords: Calcined clay lightweight aggregates, lightweight concrete, structural concrete.

\section{INTRODUÇÃO}

O concreto com agregados leves, ou concreto leve estrutural, apresenta-se como um material de construção consagrado em todo o mundo, com aplicação em diversas áreas da construção civil. A ampla utilização desse material em todo o mundo é particularmente atribuída aos benefícios promovidos pela redução da massa específica do concreto, como a redução de esforços na estrutura das edificações, a economia com formas e cimbramento, bem como a diminuição dos custos com transporte e montagem de construções pré-fabricadas $[\underline{1}, \underline{2}, \underline{3}]$.

Atualmente, devido à maior demanda da construção civil e ao déficit de agregados leves naturais, agregados leves de argila expandida aparecem como uma das únicas opções de agregados leves para a produ- 
ção de concretos estruturais leves no Brasil.

Porém, sua utilização ainda é modesta, frente ao seu potencial de utilização, estando concentrada no estado de São Paulo e em estados vizinhos, dada a localização da fábrica de argila expandida CINEXPAN, em Várzea Paulista - SP, único fabricante de agregados leves no país. Por se tratar de uma única empresa produtora, o alto custo do transporte a longas distâncias dificulta a disseminação dessa tecnologia por todo o território nacional $[\underline{2}, \underline{3}, \underline{4}, \underline{5}]$.

Uma alternativa para a disseminação da tecnologia do concreto leve estrutural por todo território nacional seria a produção de agregados leves de argila calcinada, utilizando a cerâmica vermelha, já que existem cerca de 11.000 empresas produtoras de cerâmica vermelha espalhadas por todo o território nacional [6].

Com pequenas modificações em suas linhas de produção, essas empresas poderiam produzir agregados leves de argila calcinada como mais um de seus produtos comerciais []].

Estudos preliminares indicam a viabilidade de produção e utilização desse tipo de agregado leve na construção civil, utilizando-se os polos produtivos de cerâmica vermelha espalhados por todo o território nacional $[\underline{7}, \underline{8}, \underline{9}, \underline{10}]$.

A resistência à compressão dos concretos leves depende do tipo de agregado leve, da quantidade de água utilizada, da relação água/cimento, do tipo de mistura dos componentes, do processo de lançamento e também de cura dos concretos. Já o módulo de deformação dos concretos leves está diretamente relacionado com a resistência à compressão, a quantidade de agregado e a zona de transição agregado-matriz [10, 1].

Assim, este trabalho tem como objetivo a análise da influência dos agregados leves de argila calcinada nas propriedades mecânicas de concretos produzidos com agregados leves de cerâmica vermelha, quando comparados aos concretos produzidos com agregados leves de argila expandida e com agregados convencionais de basalto.

\section{MATERIAIS E MÉTODOS}

Para a presente pesquisa, foram utilizados dois tipos de agregados leves produzidos com cerâmica vermelha, além de agregados leves de argila expandida (CINEXPAN) e agregados convencionais (basalto). Os agregados leves de argila calcinada foram confeccionados no Laboratório de Construções Rurais e Ambientais da FZEA/USP, na cidade de Pirassununga - SP.

Para a produção dos agregados leves de argila calcinada, foram coletadas amostras de solo de empresas produtoras de peças de cerâmica vermelha das cidades de Porto Ferreira/SP e Itu/SP.

As massas cerâmicas foram extrudadas com umidades próximas de seus limites de plasticidade, levando-se em consideração a umidade já existente em cada uma delas, em uma maromba de escala laboratorial produzida pela empresa "Indústria de Marombas Gelenski Ltda", modelo MVIG-05. Para a extrusão, utilizou-se boquilha de formato cilíndrico, com diâmetro de 15,0 mm. Após a extrusão, os agregados foram cortados em seu tamanho final $(15,0 \times 15,0 \mathrm{~mm})$ e armazenados em bandejas para secagem ao ar livre, como ilustra a figura 1.

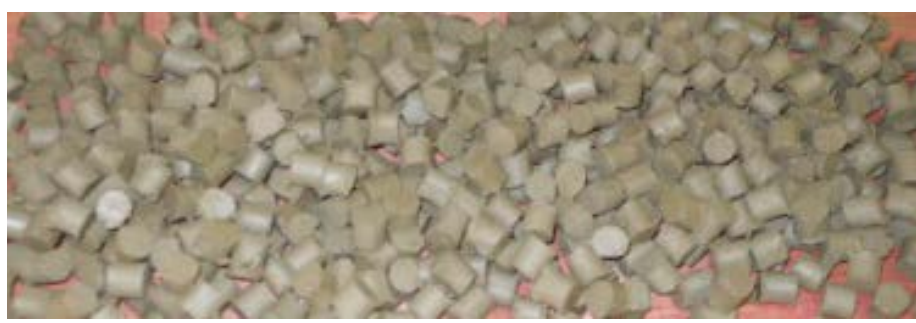

Figura 1: Agregados leves de argila calcinada produzidos na pesquisa

Após a secagem, os concretos foram levados à estufa ventilada, a uma temperatura de $60{ }^{\circ} \mathrm{C}$, por um período de 72 horas. Em seguida, foram queimados em uma mufla da marca Jung, modelo 10013, com potência de $7 \mathrm{KW}$, com temperatura de $900{ }^{\circ} \mathrm{C}$. A queima foi realizada com rampa de aquecimento de $4{ }^{\circ} \mathrm{C} /$ min. e de resfriamento de $6{ }^{\circ} \mathrm{C} / \mathrm{min}$., sendo que as peças ficaram submetidas à temperatura máxima $\left(900{ }^{\circ} \mathrm{C}\right)$ por 60 minutos.

Depois de confeccionados e caracterizados os agregados de cerâmica vermelha, os concretos foram dosados e produzidos os corpos de prova, com agregados leves de argila calcinada, argila expandida e basalto. Os corpos de prova de concreto foram nomeados de acordo com o tipo de agregado utilizado para sua confecção. Os concretos foram confeccionados no Laboratório de Construções Civil (LCC) do Instituto de Ar- 
quitetura e Urbanismo de São Carlos/SP - USP. A tabela 1 apresenta as características dos 4 tipos de agregados utilizados [11].

Tabela 1: Características físicas dos agregados graúdos utilizados na confecção dos concretos.

\begin{tabular}{c|c|c|c|c}
\hline Agregado & $\begin{array}{c}\text { Massa unitária no } \\
\text { estado solto } \\
\left(\mathbf{K g} / \mathbf{m}^{3}\right)\end{array}$ & $\begin{array}{c}\text { Massa específica } \\
\text { saturada }\left(\mathbf{K g} / \mathbf{m}^{3}\right)\end{array}$ & $\begin{array}{c}\text { Massa específica } \\
\text { aparente } \mathbf{( K g / \mathbf { m } ^ { 3 } )}\end{array}$ & $\begin{array}{c}\text { Resistência à } \\
\text { compressão } \\
\mathbf{( M P a})^{*}\end{array}$ \\
\hline Itu & 1066 & 2129 & 1791 & 39,50 \\
\hline Brita & 1543 & 2930 & 2934 & - \\
\hline Porto Ferreira & 965 & 2039 & 1555 & 18,00 \\
\hline Argila expandida & 503 & 947 & 975 & - \\
\hline
\end{tabular}

* Método adaptado da NBR 5739, para corpos de prova cerâmicos cilíndricos com base e altura de 15 mm

Conhecendo-se as características de cada um dos agregados, procurou-se manter em um mesmo patamar os consumos de cimento e areia para os quatro tipos de concreto, assim como uma relação água/cimento $(0,5)$ e o volume dos agregados graúdos para todos os concretos, de forma a se obter concretos com valores de abatimento do tronco de cone variando de $40 \mathrm{~mm}$ a $50 \mathrm{~mm}$ (valores usuais para concretos utilizados em fundações e estruturas convencionais), como ilustra a tabela 2.

Tabela 2: Consumo real de cimento, areia, agregado e água para a moldagem dos corpos de prova de concreto.

\begin{tabular}{c|c|c|c|c}
\hline Concreto & $\begin{array}{c}\text { Cimento } \\
\mathbf{( K g )}\end{array}$ & Areia (Kg) & $\begin{array}{c}\text { Agregado } \\
\mathbf{( K g )}\end{array}$ & $\begin{array}{c}\text { Relação água / ci- } \\
\text { mento }\end{array}$ \\
\hline Brita & 387,53 & 968,84 & 821,58 & 0,5 \\
\hline Argila Expandida & 377,40 & 943,51 & 271,73 & 0,5 \\
\hline Itu & 389,17 & 972,92 & 537,06 & 0,5 \\
\hline Porto Ferreira & 383,94 & 959,84 & 479,92 & 0,5 \\
\hline
\end{tabular}

Os concretos moldados foram mantidos no ambiente do laboratório por um período de 24 horas. Após esse período, foram desformados e submetidos ao processo de cura, em uma câmara úmida com umidade variando de $90 \%$ a $95 \%$ e temperatura variando de $20{ }^{\circ} \mathrm{C}$ a $23{ }^{\circ} \mathrm{C}$ até atingirem a idade de 28 dias. Transcorrido esse período, os corpos de prova de concreto foram transferidos para uma sala climatizada, com temperatura variando de $22{ }^{\circ} \mathrm{C}$ a $26{ }^{\circ} \mathrm{C}$ e umidade variando de $62 \%$ a $78 \%$, aonde permaneceram até 91 dias de idade.

O concreto no estado fresco foi submetido aos ensaios de massa específica, teor de ar incorporado e consistência pelo abatimento do tronco de cone, e no estado endurecido os concretos foram submetidos aos ensaios de resistência à compressão, resistência à tração por compressão diametral, módulo de deformação e massa específica $[\underline{12}, \underline{13}, \underline{14}, \underline{15}, \underline{16}, \underline{17}]$.

\section{RESULTADOS E DISCUSSÕES}

A apresentação e análise dos resultados está dividida em duas partes, sendo que primeiramente foram determinadas as propriedades dos concretos no estado fresco (tabela 3) e, em seguida, foram moldados os concretos para ensaios no estado endurecido.

Tabela 3: Propriedades dos corpos de prova no estado fresco.

\begin{tabular}{c|c|c|c}
\hline Concreto & $\begin{array}{c}\text { Massa específica } \\
\mathbf{( K g / \mathbf { m } ^ { 3 } )}\end{array}$ & $\begin{array}{c}\text { Abatimento do tronco } \\
\text { de cone } \mathbf{( m m})\end{array}$ & $\begin{array}{c}\text { Teor de ar incorporado } \\
\mathbf{( \% )}\end{array}$ \\
\hline Brita & 2386 & 40 & 2,03 \\
\hline Argila Expandida & 1766 & 50 & 4,59 \\
\hline Itu & 2151 & 45 & 2,66 \\
\hline Porto Ferreira & 2124 & 50 & 2,82 \\
\hline
\end{tabular}


Analisando-se a tabela 3, percebe-se que os valores de massa específica no estado fresco dos concretos variaram entre $2386 \mathrm{Kg} / \mathrm{m}^{3}$ para aqueles confeccionados com brita como agregado e $1766 \mathrm{Kg} / \mathrm{m}^{3}$ para aqueles produzidos com agregados de argila expandida. Os concretos produzidos com os agregados de Itu e de Porto Ferreira apresentaram massa específica no estado fresco iguais a $2151 \mathrm{Kg} / \mathrm{m}^{3}$ e $2124 \mathrm{Kg} / \mathrm{m}^{3}$, com redução em massa de 9,9\% e 11,0\% respectivamente, permanecendo em um patamar intermediário entre os corpos de prova produzidos com brita e os produzidos com argila expandida.

Os valores de resistência à compressão dos corpos de prova são apresentados na tabela 4.

Tabela 4: Valores de resistência à compressão dos corpos de prova de concreto

\begin{tabular}{c|c|c|c|c|c|c}
\hline \multicolumn{7}{c}{ Resistência à compressão (MPa) } \\
\hline Concreto & $\mathbf{7 ~ d i a s ~}$ & $\begin{array}{c}\text { Desvio } \\
\text { padrão }\end{array}$ & $\mathbf{2 8}$ dias & $\begin{array}{c}\text { Desvio } \\
\text { padrão }\end{array}$ & 91 dias & $\begin{array}{c}\text { Desvio pa- } \\
\text { drão }\end{array}$ \\
\hline Brita & 25,6 & 1,2 & 34,1 & 1,4 & 42,8 & 1,0 \\
\hline Argila expandida & 20,3 & 0,6 & 23,7 & 0,6 & 28,1 & 0,7 \\
\hline Itu & 18,9 & 0,7 & 23,9 & 1,0 & 29,7 & 0,7 \\
\hline Porto Ferreira & 16,2 & 0,9 & 19,8 & 1,4 & 25,8 & 1,2 \\
\hline
\end{tabular}

De acordo com a tabela 4, aos 7 dias de idade, os valores de resistência dos corpos de prova são muito próximos, uma vez que, nessa idade, a pasta de cimento ainda está em processo de hidratação e os agregados apresentam menos influência na resistência dos concretos do que em idades mais avançadas. Com o aumento da idade dos corpos de prova, ocorre um aumento da resistência da matriz e, com isso, os agregados começam a ter maior influência na resistência dos concretos, uma vez que as características dos agregados permanecem inalteradas com o aumento da idade dos concretos. Com isso, com o passar do tempo, concretos confeccionados com agregados mais resistentes apresentam um maior aumento de resistência do que concretos confeccionados com agregados menos resistentes, como ilustra a figura 2.

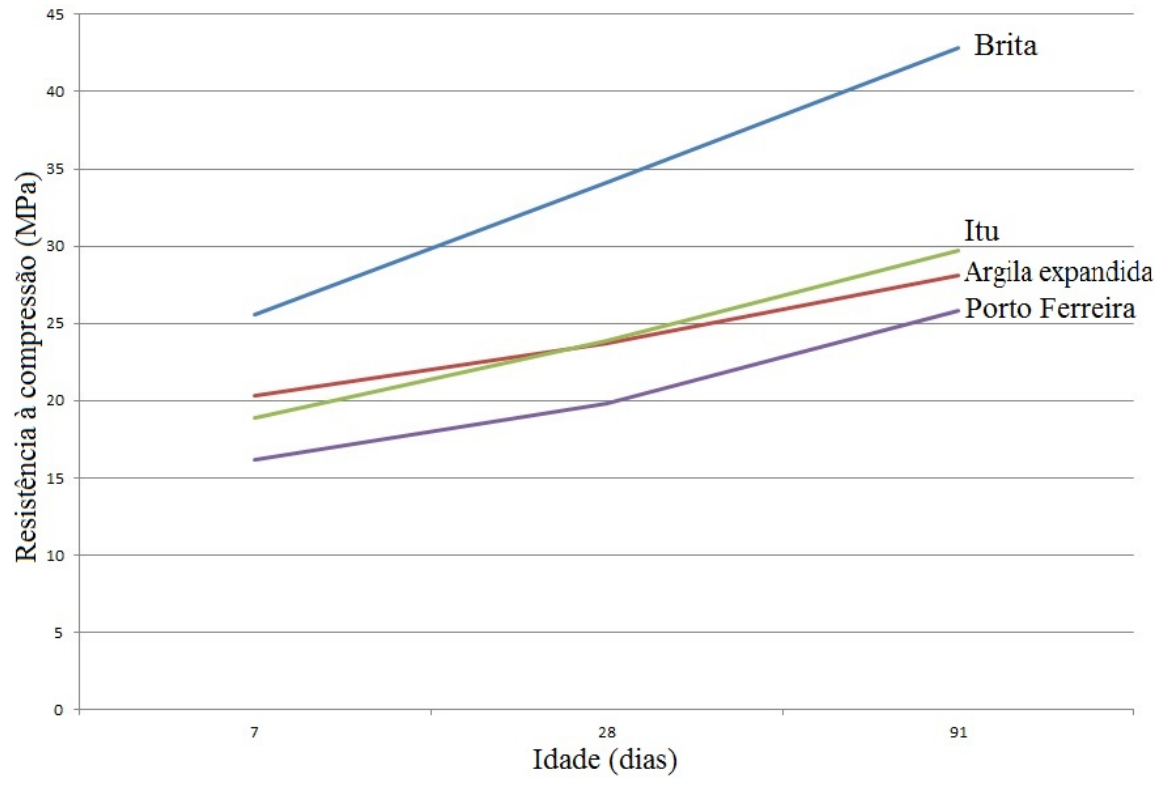

Figura 2: Resistência à compressão dos concretos

Isso fica evidente ao analisar a resistência à compressão, aos 91 dias de idade, dos concretos confeccionados com brita (agregado com valor de resistência à compressão da ordem de 120 a $150 \mathrm{MPa}$ ) [11] e com agregados leves de argila calcinada de Porto Ferreira (agregado com valor de resistência à compressão igual a 18,0 MPa), uma vez que os concretos confeccionados com brita apresentaram a maior resistência dentre todos os analisados (42,77 MPa) e os concretos confeccionados com agregados leves de Porto Ferreira apresentaram a menor resistência dentre os concretos analisados (25,82 MPa) [11]. 
Ainda analisando-se a tabela 4, observa-se que com idade de 91 dias, a resistência à compressão dos concretos variou de 25,82 MPa (concretos produzidos com agregados leves de Porto Ferreira) e 42,77 MPa (concretos confeccionados com brita).

Em todas as idades, os concretos produzidos com agregados de argila expandida e Itu apresentaram valores muito próximos de resistência à compressão, sendo eles inferiores aos valores apresentados pelos concretos produzidos com brita (agregado mais resistente dentre os analisados) e superiores aos valores apresentados pelos produzidos com agregados leves de Porto Ferreira (agregado menos resistente dentre os analisados).

Os valores de massa específica aparente (estado endurecido) e fator de eficiência (Fe) (relação direta entre a resistência à compressão e a massa específica aparente dos concretos) dos concretos são apresentados na tabela 5.

Tabela 5: Massa específica aparente e fator de eficiência dos corpos de prova de concreto.

\begin{tabular}{|c|c|c|c|}
\hline Concreto & $\begin{array}{c}\text { Massa específica aparente } \\
\qquad\left(\mathrm{Kg} / \mathrm{m}^{3}\right)\end{array}$ & Desvio padrão & $\begin{array}{l}\text { Fator de eficiência } \\
\text { (MPa.dm³/Kg) }\end{array}$ \\
\hline Brita & 2235 & 12,98 & 19,14 \\
\hline Argila expandida & 1608 & 12,70 & 17,46 \\
\hline Itu & 1948 & 1,30 & 15,25 \\
\hline Porto Ferreira & 1896 & 7,05 & 13,62 \\
\hline
\end{tabular}

Analisando-se a tabela 5, percebe-se que os agregados têm grande influência na massa específica aparente dos concretos, uma vez que os concretos confeccionados com agregados mais densos (brita) apresentaram massa específica maior do que os concretos confeccionados com agregados menos densos (argila expandida).

Ainda analisando a tabela 5, percebe-se que os concretos confeccionados com os agregados de Porto Ferreira e Itu apresentam valores de massa específica aparente em um patamar intermediário quando comparados aos dos concretos confeccionados com argila expandida e brita, sendo que a redução de massa para os concretos com agregados leves de itu foi de $12,8 \%$ e para os concretos com agregados leves de Porto Ferreira foi de 15,2\%, quando comparados aos concretos confeccionados com brita.

O fator de eficiência (Fe) dos concretos variou de 13,62 $\mathrm{MPa} \cdot \mathrm{dm}^{3} / \mathrm{Kg}$ para os corpos de prova de concreto produzidos com os agregados leves de Porto Ferreira a 19,14 MPa.dm³/Kg para os concretos produzidos com brita, como ilustra a figura 3.

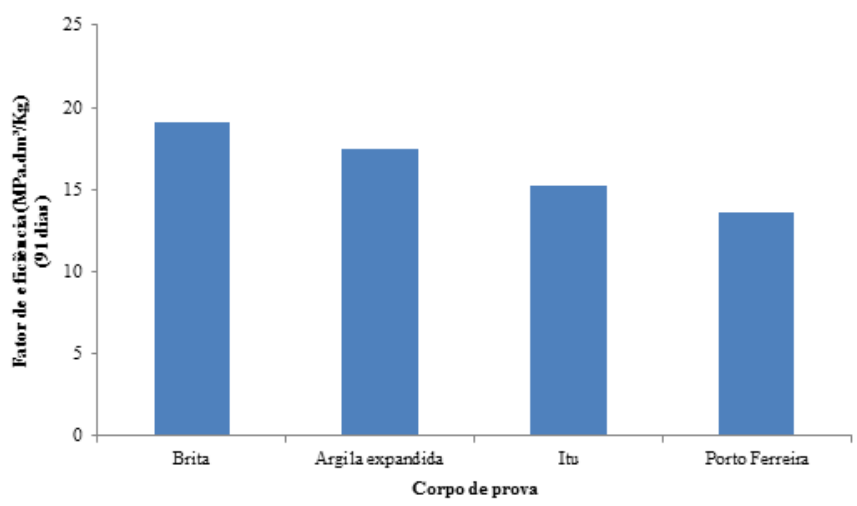

Figura 3: Fator de eficiência dos concretos 
Os valores da resistência à tração por compressão diametral dos concretos são apresentados na tabela 6 .

Tabela 6: Valores de resistência à tração dos concretos

\begin{tabular}{c|c|c|c}
\hline Concreto & $\begin{array}{c}\text { Resistência à } \\
\text { Tração (MPa) }\end{array}$ & $\begin{array}{c}\text { Desvio Padrão } \\
\text { (MPa) }\end{array}$ & $\begin{array}{c}\text { Resistência à tração / Resistência à com- } \\
\text { pressão (28 dias) (\%) }\end{array}$ \\
\hline Brita & 2,92 & 0,11 & 8,57 \\
\hline Argila expandida & 1,80 & 0,55 & 7,60 \\
\hline Itu & 2,29 & 0,61 & 9,57 \\
\hline Porto Ferreira & 1,78 & 0,37 & 8,99 \\
\hline
\end{tabular}

Analisando-se a tabela 6, percebe-se que a relação entre a resistência à tração e a resistência à compressão dos concretos são muito semelhantes, variando de 7,6\% para os concretos confeccionados com agregados de argila expandida a 9,5\% para os concretos confeccionados com agregados leves de Itu, o que é um indício de que os agregados confeccionados com matérias primas de Porto Ferreira e Itu não alteraram os valores da relação "resistência à tração/resistência à compressão" dos concretos, normalmente em torno de $10 \%$.

A tabela 7 apresenta os valores dos módulos de deformação dos concretos aos 28 dias de idade.

Tabela 7: Módulo de deformação dos concretos

\begin{tabular}{c|c|c}
\hline Concreto & $\begin{array}{c}\text { Módulo de deformação } \\
\text { (GPa) }\end{array}$ & Desvio Padrão (GPa) \\
\hline Brita & 36,63 & 0,75 \\
\hline Argila expandida & 20,44 & 2,64 \\
\hline Itu & 19,48 & 0,51 \\
\hline Porto Ferreira & 17,41 & 1,58 \\
\hline
\end{tabular}

Observando-se a tabela 7, percebe-se que os valores dos módulos de deformação dos concretos com agregados leves foram inferiores aos valores do módulo de deformação dos concretos produzidos com brita, uma vez que os agregados leves apresentam valores de resistência à compressão e módulo de deformação inferiores aos agregados convencionais (brita) e, por isso, os agregados leves tentem a romper antes do que a brita e da pasta de cimento.

Isso fica evidente ao compararmos os valores do módulo de deformação dos concretos confeccionados com brita e dos confeccionados com agregados leves de Porto Ferreira. Os concretos confeccionados com brita apresentaram o maior módulo de deformação dentre os analisados (36,63 GPa), e a brita apresenta a maior resistência dentre os agregados analisados (na ordem de 120 a 150 MPa). Já os concretos confeccionados com agregados leves de argila calcinada de Porto Ferreira apresentaram os menores valores de módulo de deformação (17,41 GPa), assim como os agregados leves de argila calcinada de Porto Ferreira apresentaram as menores valores de resistências à compressão (18,0 MPa) [11].

\section{CONCLUSÕES}

Com os resultados obtidos neste trabalho, há indicações de que a produção de concretos com agregados leves de argila calcinada pode ser viável, com destaque para os seguintes aspectos:

- No estado endurecido, os valores de massa específica aparente dos concretos com agregados leves de Itu $\left(1948 \mathrm{Kg} / \mathrm{m}^{3}\right)$ e Porto Ferreira $\left(1896 \mathrm{Kg} / \mathrm{m}^{3}\right)$ apresentaram-se em um patamar intermediário entre os valores de massa específica dos concretos confeccionados com basalto $\left(2235 \mathrm{Kg} / \mathrm{m}^{3}\right)$ e argila expandida (1608 $\mathrm{Kg} / \mathrm{m}^{3}$ ), tendo-se observado uma redução em massa de $12,8 \%$ e $15,2 \%$ para os concretos com agregados leves de Itu e Porto Ferreira, quando comparados aos concretos com basalto como agregado;

- Os valores das resistências à compressão dos concretos moldados para essa pesquisa variaram de 25,82 MPa (concretos confeccionados com agregados leves de argila calcinada proveniente de Porto Ferreira) a 42,77 MPa (concretos confeccionados com brita), aos 91 dias de idade; 
- Os concretos confeccionados com agregados leves de argila calcinada de Itu e Porto Ferreira atingiram patamares similares de resistência à compressão e módulo de deformação, quando comparados aos valores observados para os concretos produzidos com argila expandida, porém suas massas específicas aparentes foram superiores às observadas nos corpos de prova de concreto com argila expandida;

- Portanto, agregados leves de argila calcinada mostram-se como uma alternativa viável para utilização em concretos estruturais leves do ponto de vista de desempenho mecânico, já que os concretos confeccionados com agregados leves de argila calcinada apresentaram características similares aos confeccionados com argila expandida, além da possibilidade de disseminação desta tecnologia por todo o território nacional, já que existe uma grande quantidade de empresas produtoras de cerâmica vermelha espalhadas por todo o território nacional. Exalta-se aqui a necessidade de pesquisas futuras acerca da durabilidade dos concretso leves estruturais confeccionados com agregados leves de argila calcinada, uma vez que estes parâmetros são de fundamental importância para a vida útil das estruturas de concreto.

\section{AGRADECIMENTOS}

À CAPES, ao CNPq e à FINEP pelo apoio financeiro para o desenvolvimento deste trabalho, ao Laboratório de Mecânica dos Solos do Departamento de Geotecnia da EESC/USP, ao Laboratório de Construção Civil do IAU/USP, ao Instituto de Geociências da USP, ao laboratório de Construções Rurais e Ambiência da FZEA/USP e às empresas, Selecta blocos (Grupo Estrutural) e Maristela Telhas Ltda. (Top Telha) por fornecerem matéria prima para essa pesquisa.

\section{BIBLIOGRAFIA}

[1] ZHANG, M. H., GJpRV, O. E., "Mechanical Properties of High-Strength Lightweight Concrete", ACI Materials Journal, v. 88, n. 3, pp. 240-247, Mai. 1991.

[2] ROSSIGNOLO, J. A., AGNESINI, M. V. C. Concreto leve estrutural. In: ISAIA; G. C. (Org.) Concreto: Ensino, Pesquisa e Realizações. IBRACON, v. 2, pp. 1333-1362, São Paulo, 2005.

[3] ROSSIGNOLO, J. A. Concreto leve estrutural: Produção, propriedades, microestrutura e aplicações. 1 ed., São Paulo, Editora PINI, 2009.

[4] TEZUKA, Y. Concreto leve à base de argila expandida, Dissertação de M.Sc., Escola Politécnica da Universidade de São Paulo, São Paulo-SP, 1973.

[5] SOBRAL, H. S., Concretos leves estruturais: Tipos e comportamento estrutural. Publicação ET-86, São Paulo, ASSOCIAÇÃO BRASILEIRA DE CIMENTO PORTLAND - ABCP, 1996.

[6] SERVIÇO BRASILEIRO DE APOIO ÀS MICRO E PEQUENAS EMPRESAS - SEBRAE, Cerâmica vermelha para construção: telhas, tijolos e tubos. Estudos de Mercado, São Paulo, SEBRAE/ESPM, 2008.

[7] CABRAL, G. L. L., Metodologia de Produção e Emprego de Agregados de Argila Calcinada para Pavimentação, Dissertação de M.Sc., Instituto Militar de Engenharia, Rio de Janeiro, RJ, Brasil, 2005.

[8] CABRAL, E. M., SÁ, R. J., VIEIRA, R. K., et al., "Utilização de massas cerâmicas na produção de agregado sintético de argila calcinada para uso em concreto", Cerâmica, v. 54, n. 332, pp. 404-410, Out/Dez., 2008.

[9] SOARES, A. L. C. P., BATISTA, F. G. S., CABRAL, G. L. L., Estudo da viabilidade técnica do agregado de argila calcinada para a pavimentação da Amazônia. Projeto de Fim de Curso, Instituto Militar de Engenharia-IME, Rio de Janeiro, 1998.

[10] CHANDRA, S. BERNTSSON, L. Lightweight Aggregate Concrete, 1 ed., Norwich, Noyes Publications, 2002.

[11] SANTIS, B. C., ROSSIGNOLO, J. A., SICHIERI, E. P., et al., "Caracterização de massas cerâmicas do Estado de São Paulo para a produção de agregados leves para concreto”, Cerâmica, v. 59, n. 350, pp. 198205, Abr./Jun. 2013.

[12] ASSOCIAÇÃO BRASILEIRA DE NORMAS TÉCNICAS, NBR 9833: Concreto Fresco - Determinação da Massa Específica e do Teor de Ar pelo Método Gravimétrico, Rio de Janeiro, 2008.

[13] ASSOCIAÇÃO BRASILEIRA DE NORMAS TÉCNICAS, NBR NM 67: Concreto - Determinação da consistência pelo abatimento do tronco de cone, Rio de Janeiro,1998 .

[14] ASSOCIAÇÃO BRASILEIRA DE NORMAS TÉCNICAS, NBR 5739: Ensaio de compressão de corpos-de-prova cilíndricos de concreto, Rio de Janeiro, 2007.

[15] ASSOCIAÇÃO BRASILEIRA DE NORMAS TÉCNICAS. NBR 7222: Concreto e argamassa - De- 
terminação da resistência à tração por compressão diametral de corpos de prova cilíndricos, Rio de Janeiro, 2011.

[16] ASSOCIAÇÃO BRASILEIRA DE NORMAS TÉCNICAS. NBR 8522: Concreto - Determinação do módulo elástico de elasticidade à compressão, Rio de Janeiro, 2008.

[17] ASSOCIAÇÃO BRASILEIRA DE NORMAS TÉCNICAS. NBR 9778: Argamassa e Concreto Endurecidos - Determinação da Absorção de Água, Índice de Vazios e Massa específica, Rio de Janeiro, 2005. 